\title{
Editorial: Special Issue on Aging in Indigenous Populations
}

The Truth and Reconciliation Commission of Canada (2015) called for a widespread recognition that the current state of health in Indigenous populations in Canada is a "direct result of previous Canadian government policies, including residential schools" (p. 322). The Commission also emphasized the importance of identifying and closing the current gaps in health outcomes and of honouring Indigenous healing practices. It was in this context that the Canadian Journal on Aging/La Revue canadienne $d u$ viellissement invited submissions that address issues of aging in Indigenous populations in Canada and internationally.

The Canadian Journal on Aging/La Revue canadienne du vieillissement is proud to present this Special Issue on Aging in Indigenous Populations. In this issue, we feature 15 articles exploring some of the most recent and important research being done by, and with, Indigenous peoples and communities. The articles in this collection explore a diverse range of topics, including: experiences of racism, participatory research methods, culturally safe health programs, and perspectives on successful aging. We thank all of the authors and study participants for their contributions, and encourage ongoing discussion and exchange of ideas around this critical area of research.
For this issue, we invited authors to include - in addition to the usual French and English abstracts - an additional abstract in an Indigenous language relevant to the published work. This was possible for a number of articles in the collection.

For this special issue, I am grateful for the support and encouragement we have received from the Canadian Institutes of Health Research Institute of Indigenous Peoples' Health and Institute of Aging, as well as from the Social Sciences and Humanities Research Council through their Aid to Scholarly Journals Program.

I am particularly grateful for the expertise and leadership provided by the guest editor for this special issue, Dr. Jennifer Walker.

Paul Stolee

Editor-in-Chief

\section{Reference}

Truth and Reconciliation Commission of Canada. (2015). Honouring the truth, reconciling for the future: Summary of the final report of the Truth and Reconciliation Commission of Canada. Retrieved 1 October 2019 from http://www.trc.ca/assets/pdf/Honouring_the_Truth_ Reconciling_for_the_Future_July_23_2015.pdf 